\title{
A phased array ultrasound roller probe for automated in-process/interpass inspection of multipass welds
}

\author{
Randika K. W. Vithanage, Ehsan Mohseni, Zhen Qiu, Charles MacLeod, Yashar Javadi, Nina \\ Sweeney, Gareth Pierce, Anthony Gachagan.
}

\begin{abstract}
Non-destructive inspection of multi-pass welds for defects is traditionally performed once all layers have been deposited and the sample is at ambient temperature and therefore can lead to complicated and expensive rework, reduced throughput and higher lead times. By performing inspection either as the weld is deposited, or between weld passes, it is possible to identify defects earlier in the process and rectify them. Traditional ultrasonic inspection is severely limited in this application due to the high temperatures associated with the welding process and therefore, the authors describe a novel high-temperature ultrasound phased array roller probe to perform robotically delivered in-process inspection of multipass welds. The new roller probe is able to operate at temperatures up to $350{ }^{\circ} \mathrm{C}$ and perform angled weld inspection using $55^{\circ}$ transverse waves. The wheel probe's endless rotation enables continuous inspection and makes it well suited to integrate within automated environments commonly employed for high integrity multipass welding applications. The probe demonstrated capability to detect calibration side drilled holes at room temperature and artificial defects embedded into a real weld at high temperature. The experimental results indicate potential to industrialise this prototype in the future.
\end{abstract}

Index Terms - Automated in-process inspection; High temperature inspection; Phased array ultrasound roller probe.

\section{INTRODUCTION}

$\mathrm{T}$ RADITIONAL inspection of welded components is performed after the entire weld has been deposited and the sample cooled to ambient temperatures [1-3]. In multipass welds, this therefore runs the risk of defects in early passes not being detected until after final deposition. This makes rectification of defects more complex, potentially scrapping the entire part, and start manufacturing process all over $[4,5]$. By shifting the point of inspection to between weld

Manuscript received April 20, 2020; revised October 01, 2020; accepted November 18, 2020. Corresponding Author: Randika K. W. Vithanage.

All authors are with the Centre for Ultrasonic Engineering, Department of Electronic and Electrical Engineering, University of Strathclyde, Glasgow, United Kingdom.

(e-mail: randika.vithanage@strath.ac.uk, ehsan.mohseni@strath.ac.uk, zhen.qiu@strath.ac.uk, charles.macleod@strath.ac.uk, yashar.javadi@strath.ac.uk, nina.wweeney@strath.ac.uk, s.g.pierce@strath.ac.uk and a.gachagan@strath.ac.uk). passes, it would be possible to pick up these defects earlier and reduce expensive rework, increase throughput, optimize product costs and decrease lead times. Unfortunately, it is generally not desirable to let the component cool to ambient between welding passes to allow traditional inspection to be conducted. This is because repeated heating and cooling cycles would adversely affect the microstructure of both the weld and the heat affected zone in the substrate. In order to overcome this challenge, the concept of merging welding and inspection into a single process directly at the point of welding is currently being researched [6,7]. Such inspection strategies can be realized through automating both welding and inspection to perform non-destructive testing (NDT) at high temperatures.

Automated NDT systems for inspection of welds and joints is becoming increasingly popular offering higher consistency, speed and repeatability when compared to human operators [8]. In many industrial sectors, ultrasonic testing (UT) is the primary choice for inspection of welded joints when compared to other NDT methods, such as radiography and eddy current testing, owing to its non-hazardous application, capability to perform bulk inspection due to deep penetration, and better detection capability of different defect types $[9,10]$. In addition, UT received further acceptance within industry after the introduction of phased array ultrasonic testing (PAUT) due to its ability to steer the beam electronically, focus energy at a certain point and minimize inspection time [11]. With phased array transmission and reception approaches such as beam forming, the probe can be positioned stationary alongside a weld while the inspection beam angle is swept electronically to scan the weld geometry [10].

The common practice for the inspection of welded sections using PAUT is to beam form for sectorial scanning. Subsequently, the angular sweep results are presented in the form of sectorial scan (S-Scan) images where A-scans are plotted beside each other maintaining their insonification angle. A standard manual weld inspection assembly is shown in Figure 1 (a) with the resultant S-Scan image. The UT assembly is positioned on a weld calibration block with $2 \mathrm{~mm}$ side drilled holes (SDH). A $5 \mathrm{MHz}-64$ element phased array is used with an angled wedge to generate $55^{\circ}$ transverse $(\mathrm{T})$ waves into the welded region. The wider range of beam angles in the S-scan encourages the detection of defects oriented randomly.

Typical arc fusion-welding environments are hostile in both temperatures and electromagnetic interferences and therefore, challenges linked to in-process inspection of welds are nontrivial [6]. Such challenges include, but are not limited to, high 
temperatures, minimal use of liquid coupling, surface and geometric variations, electrical isolation between transducer and workpiece and various other specifications vital for automation such as ability to manipulate on a given workpiece with minimal hardware deterioration. Although there are solid high temperature (HT) wedge assemblies commercially available, which could be used to perform discrete manual inspections at temperatures up to $300{ }^{\circ} \mathrm{C}$ for a very limited period of time [12], they lack the ability to perform continuous automated scans especially over curved or complex geometries. Also, fixed geometries of these HT wedges can restrict the application to the inspection of components with specific structural shapes [13].

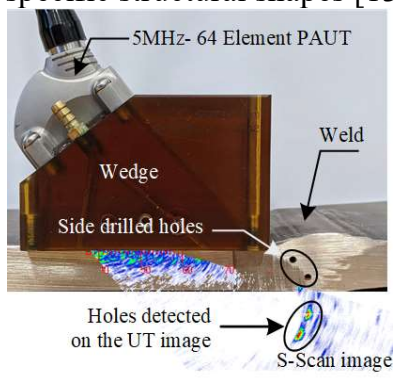

(a)

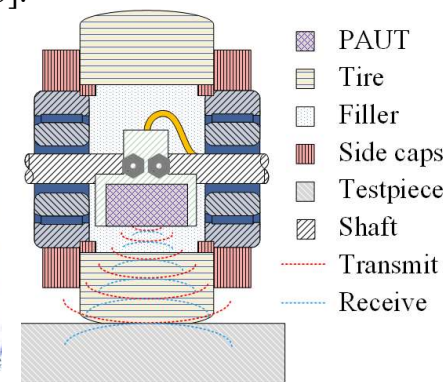

(b)
Fig.1. (a) Manual weld inspection assembly using a phased array mounted to a high temperature wedge and (b) schematic of a roller probe.

Therefore, this work aims to expand the scope of previous research carried out on in-process inspection of multipass welds by introducing a novel phased array ultrasound roller probe that can be deployed robotically [7,14]. A typical roller probe is an ultrasound inspection device that encompasses a single element or PAUT transducer within a wheel [15]. Shown in Figure 1 (b) is the fundamental arrangement of a roller probe with illustrative transmit-receive ultrasound wave propagation. A typical roller probe consists of an ultrasound transducer configured to have a $0^{\circ}$ tilt and retained static with respect to the main shaft. The roller probe tires are generally made of rubber like materials and free to rotate. Individual roller probes are designed to have distinct fillers depending on mechanical and UT requirements.

Although there are number of commercially available roller probes, they do not meet the demanding requirements of inprocess weld inspection when it comes either to higher temperature compliance or T wave inspection of welds. Due to the geometry of partially filled welds, it is impractical to deploy an ultrasound transducer on top of the weld beads during in-process inspection. Therefore, as is common in standard post-weld inspection, the probe assembly should be scanned alongside the weld performing continuous angled inspection using $\mathrm{T}$ waves.

This manuscript is focused on the design and development of a novel liquid filled high temperature roller probe that encompasses a $5 \mathrm{MHz}, 64$ element linear phased array with 0.5 $\mathrm{mm}$ pitch and $10 \mathrm{~mm}$ elevation. Shown in Figure 2 is a schematic of the PAUT roller probe performing angled inspection of welds using $55^{\circ} \mathrm{T}$ wave where upper extremity (UE) and lower extremity (LE) of sectorial scan beams are indicated. Through wave propagation analysis, knowledge of the different material impedances and wave refraction, it was realised that mode conversion model for a half-skip trip of the wave into the steel sample is L-L-T-T-L-L (L: Longitudinal and T: Transvers), where the L-L-T part is the transmission of the wave within water, rubber, and test material domains and the T-L-L is associated with the return trip to the array.

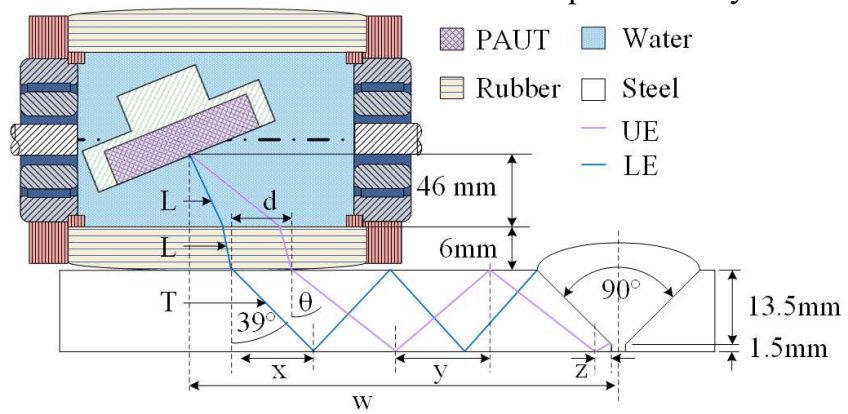

Fig. 2. Schematic of the new PAUT roller probe performing angled weld inspection using $55^{\circ} \mathrm{T}$-wave.

The PAUT roller probe described here has the ability to conform to the geometric imperfections/variations of the workpiece and can be configured to either travel behind a weld torch in a pre-calculated distance as each weld bead is deposited or to perform scans after individual weld passes at a higher speed. The paper is organized as follows: section II describes modelling and design of the PAUT roller probe, section III describes experimental setup, section IV presents the results, and section $\mathrm{V}$ concludes the present work and summarizes the future work.

\section{DESIGN AND DEVELOPMENT}

The overall design strategy of roller probe was influenced by several factors such as: (i) HT requirements for the roller probe's tire as this is the part directly in contact with the test material, (ii) acoustic properties of the filler and the tire materials, (iii) commercial availability of tire material and their malleability, (iv) the size of ultrasound array and its maximum operating temperature, (v) internal pressure of the roller probe's liquid domain, (vi) transducer cable routing limitations, and (vii) necessary ingress protection (IP) rating levels.

First, a simplified time-transient finite element model (FEM) of the roller probe assembly was created to identify key material parameters that affect the internal temperature distribution. As a result, an array consisting of feasible combinations of geometric and material properties was created. Subsequently, a range of commercially available HT tire materials, mostly constituted from silicon rubbers were procured. The optimal tire thickness was estimated by incorporating physical properties of the best suited rubber candidate into a detailed parametric model. Afterwards, an acoustic model of the roller probe assembly was developed using the estimated tire thickness and material acoustic properties. These results were included in the computer-aideddesign (CAD) of the PAUT roller probe, which allowed development of a working prototype. The following subsections II.A. to II.D. provide a comprehensive description of the procedures undertaken for thermal modelling, material selection, acoustic and mechanical modelling of the PAUT roller probe. 


\section{A. Mechanical design}

The CAD of the PAUT roller probe was created using a 3D modelling software. Here, the complete model was parameterized and linked in part level to make the final assembly flexible and easily reconfigurable. The diameter and length of the roller probe tire were determined based on the acoustic window estimated in II.D., the size, position and orientation of the array, and transducer's cable routing sequence. The PAUT transducer cable was simulated in CAD and observed for any bend radius violations. All cable glands and seals are rated at IP 67 and able to tolerate temperatures up to $120{ }^{\circ} \mathrm{C}$. The absorber's optimal shape, position, face pattern and orientation were designed by determining the ray tracing and spread of acoustic wave reflected from the water/tire interface. A mechanical proof of concept was assembled using a 3D printed rubber tire and used to verify the water-tightness at $0.20 \sim 0.25$ bar hydraulic pressure. The CAD illustration, the internal assembly and the completed PAUT roller probe assembly are illustrated in Figure 3.

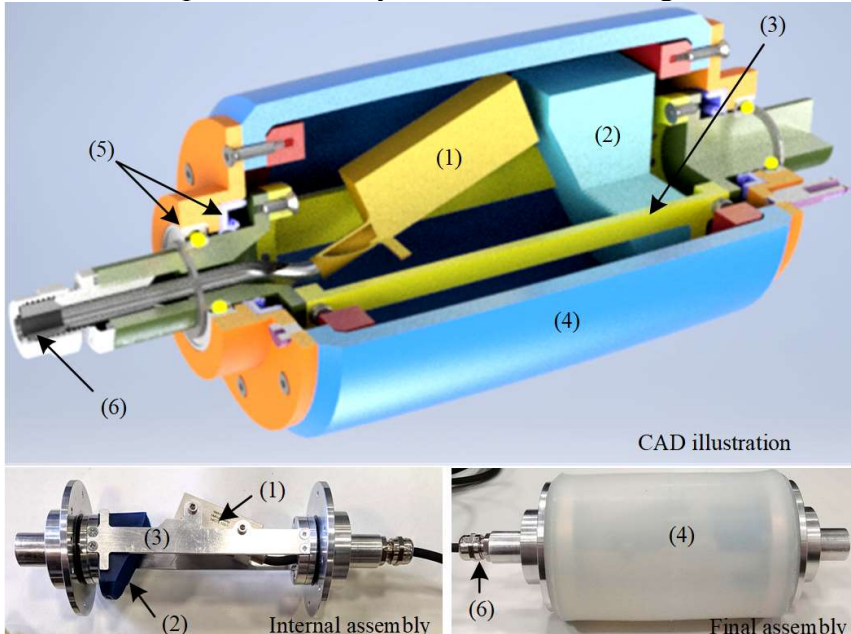

Fig. 3. Computer aided illustration and physical assembly of the PAUT wheel probe indicating (1) A $5 \mathrm{MHz}-64$ element PAUT transducer, (2) absorber, (3) holding structure, (4) HT tire, (5) bearing and shaft seal and (6) cable gland

\section{B. Estimation of key thermal parameters}

It was considered that the roller probe tire needs to withstand temperatures beyond $250{ }^{\circ} \mathrm{C}$ to accommodate most preheat and post-heat temperature requirements in welding [16]. The maximum operating temperature of a typical immersion type PAUT transducer is around $55{ }^{\circ} \mathrm{C} \sim 60{ }^{\circ} \mathrm{C}$ which is mainly constrained by the maximum operating temperatures of filler polymers and materials used to bond interconnects. Therefore, the designated maximum temperature within the roller probe's liquid domain was considered to be $50{ }^{\circ} \mathrm{C}$. Also, it was assumed that the roller probe tire acts as the initial thermal barrier and therefore, it is important to select a tire fabrication material that best suits the thermal requirements. Therefore, a simplified time-transient thermal FEM as shown in Figure 4 was generated and parameterized to identify the thermal properties of the tire material that are the most significant to the temperature within the roller probe.

The rubber height $(\mathrm{H})$, thermal conductivity $(\mathrm{K})$, specific heat capacity (C) and density (D) were parametrically varied.
The tilted or PAUT transducer surface temperature $T_{P}$ was measured for each parameter set. A $15 \mathrm{~mm}$ thick steel plate $\left(\mathrm{H}_{\mathrm{w}}\right)$ was considered together with a $36 \mathrm{~mm}$ standoff $\left(\mathrm{H}_{\mathrm{L}}\right)$ based on an existing high temperature wedge assembly. The length of the rubber sample (L) was assumed to be $80 \mathrm{~mm}$. A $350{ }^{\circ} \mathrm{C}$ constant temperature was assigned to the baseplate and welded region. Thermo-mechanical properties of water were incorporated into the liquid domain and natural convection in stagnant air was considered. This transient simulation was performed for a duration of 15 minutes considering the roller probe should withstand an initial scan period of at least 10 minutes - which is comparable to the existing commercial HT wedge assemblies [17].

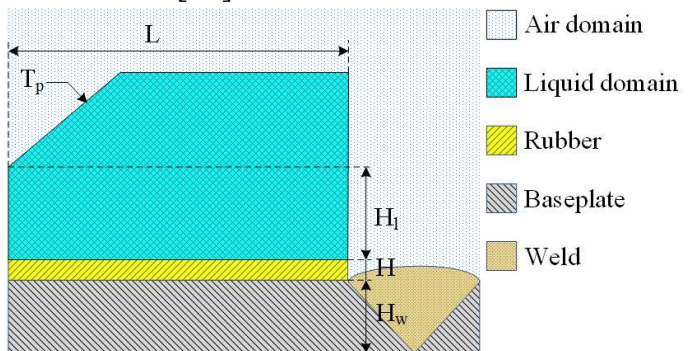

Fig. 4. Illustration of the parametric simulation setup to estimate key material parameters

The correlation of $\mathrm{K}, \mathrm{C}, \mathrm{D}$ and $\mathrm{H}$ with $\mathrm{T}_{\mathrm{P}}$ were observed. As depicted in Figure 5 (a), it can be realized that parameters $\mathrm{K}$ and $\mathrm{H}$ significantly contribute to $\mathrm{T}_{\mathrm{P}}$. Therefore, further investigations were narrowed down to analyse $\mathrm{K}$ and $\mathrm{H}$ of a given tire material saving investigational time and cost. For initial material procurement purposes, a trade-off between these parameters were analysed by means of Pareto front indices - see Figure 5 (b). A higher Pareto front index indicates a substantial trade-off of one objective over the other. Therefore, any combination of $\mathrm{K}$ and $\mathrm{H}$ for a specific $\mathrm{T}_{\mathrm{P}}$ indicated by a lower Pareto index or first Pareto front was perceived as a realistic parameter set to proceed [18]. This information was taken into consideration to shortlist potential roller probe tire materials.

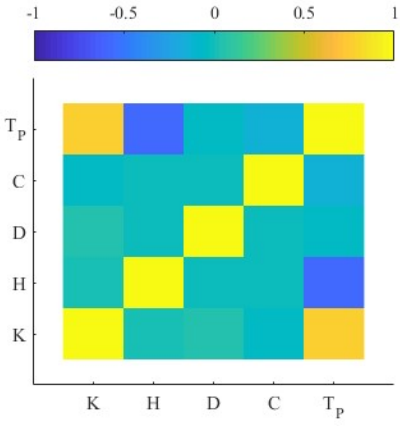

(a)

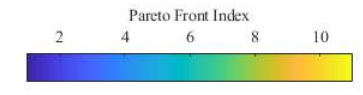

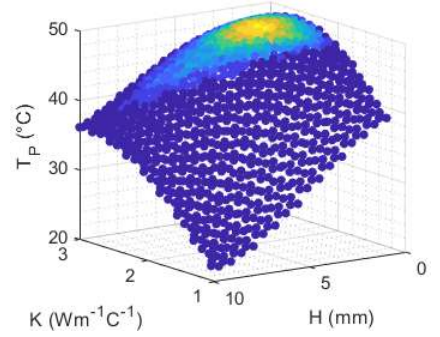

(b)
Fig. 5. (a) Pearson's correlation matrix of K, C, D, H and TP; (b) Pareto indices showing trade-off between $\mathrm{K}, \mathrm{H}$ and TP.

\section{Materials and their properties}

A number of commercially available HT rubber samples were procured based on thermal characteristics identified in Section II.B. The acoustic properties of these materials were tested to identify potential candidates to fabricate PAUT roller probe tire and the acoustic absorber. The absorber was placed 
beside the PAUT transducer to reduce sound reverberation within the wheel and therefore, to increase the signal-to-noise ratio.

As proposed in [19], the acoustic properties of the rubbers were measured using an immersion through-transmission technique to avoid geometric deformation of the samples - see Figure 6. A pair of $5 \mathrm{MHz}$ single element transducers, one for transmitting and one for receiving, were positioned and aligned in a water tank filled with degassed water. The rubber samples were mounted on a sample holder and placed between the transducer pair in the water path. A-Scan signals were captured on the receiver using an oscilloscope, with and without the rubber samples in place, capturing changes in both travel time and impulse amplitude. The bulk L wave velocities and attenuations of the rubber samples were then calculated using the travel time and impulse voltage [19].

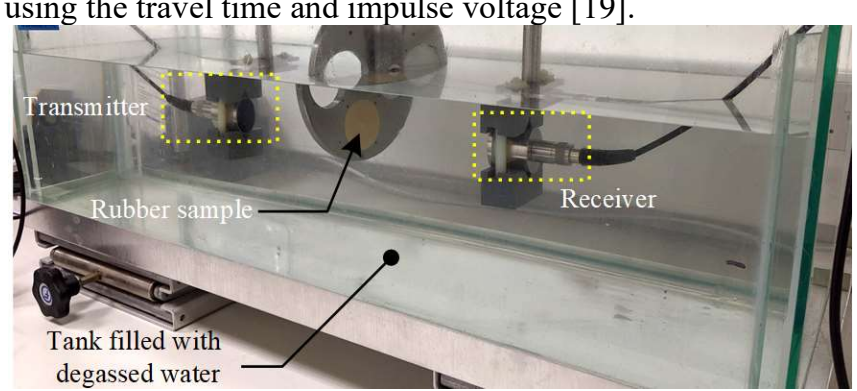

Fig. 6. Material characterising test ring indicating transmit-receive transducer configuration, immersion tank and sample setup.

As described in Section I using Figure 2, the dominant energy within the rubber layer which contributes to the imaging capability of the roller probe assembly is L wave, the bulk $\mathrm{T}$ wave properties of the rubber samples were not presented in this paper. The measured acoustic properties of the rubber samples are presented in Figure 7. The acoustic impedances of all samples are within the range of $1.1-1.9$ MRayls, which matches to the acoustic impedance of possible liquid fillers such as general oil with 1.1 MRayls or water with 1.5 MRayls. The rubber commercially known as "HNBR NFiller" was found to have the highest acoustic damping effect with an attenuation of $6.4 \mathrm{~dB} / \mathrm{mm}$ at $5 \mathrm{MHz}$. Hence, it was considered as a potential rubber material to fabricate acoustic absorber which has a maximum well beyond the designated maximum temperature of roller probe's liquid domain.

The rubber samples Peroxide 30, HT-Silicone S20A and HT-Silicone 40A [20] were selected as potential candidates to fabricate the phased array roller probe tire, due to their higher temperature compliance that exceeds $300{ }^{\circ} \mathrm{C}$. Thermal conductivity, specific heat capacity and density of these rubbers were experimentally measured and demonstrated to have a standard deviation of $0.0063 \mathrm{~W} / \mathrm{m}-\mathrm{K}, 162.14 \mathrm{~J} / \mathrm{kg}-\mathrm{K}$ and $47.53 \mathrm{~kg} / \mathrm{m}^{3}$, respectively. As dispersion of key thermomechanical properties is insignificant, rubber sample HTSilicone S20A was opted for tire fabrication - which is an acoustically optimized proprietary material that could withstand up to $350{ }^{\circ} \mathrm{C}$ in long exposure. This rubber has a longitudinal attenuation of $0.87 \mathrm{~dB} / \mathrm{mm}$ at $5 \mathrm{MHz}$ with an acoustic impedance of 1.12 MRayls.

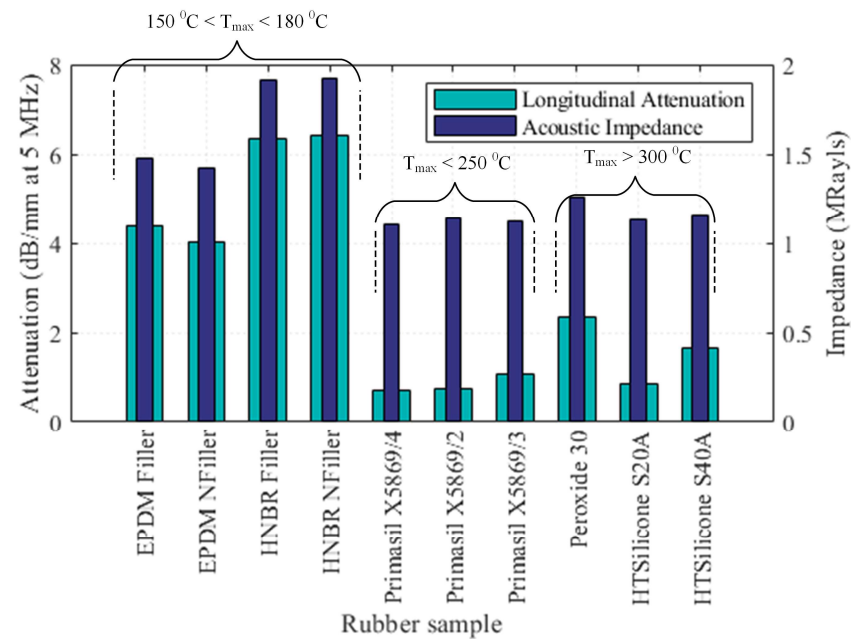

Fig. 7. Acoustic properties of high temperature rubber materials.

The material characterisation was carried out at room temperature $\left(22{ }^{\circ} \mathrm{C}\right)$ due to high-temperature limitations associated with the test-rig and the UT hardware. However, the absorber material "HNBR NFiller" and tire material "HTSilicone S20A" were further tested at elevated temperature to understand the comparative variation in attenuation due to temperature. The rubber samples were heated to $100{ }^{\circ} \mathrm{C}$ using a hotplate and the attenuation measured using a single element $5 \mathrm{MHz}$ ultrasound transducer protected by a high temperature compliant PEI polymer standoff and downward force of $5 \mathrm{~N}$. Olympus H-2 high temperature gel [24] was used between each material interface. The attenuation of HNBR NFiller was reduced by seven folds to $0.97 \mathrm{~dB} / \mathrm{mm}$ and the attenuation of HT-Silicone S20A was reduced by 2.5 times to $0.34 \mathrm{~dB} / \mathrm{mm}$ at $100{ }^{\circ} \mathrm{C}$ compared to room temperature. These test conditions are considered non-ideal as per [19] as the rubbers may have deformed due to the applied force of the ultrasound transducer.

\section{Estimation of optimized tire thickness}

A thicker tire acts as a better thermal barrier but further attenuates any acoustic wave. Therefore, it is important to minimize the roller probe's tire thickness for a predetermined scan period. This time window is primarily governed by the thermal propagation across the tire and the maximum operating temperature of the ultrasound transducer. It should be noted that a 10 minutes scan time for a given weld plate at $350{ }^{\circ} \mathrm{C}$ is chosen based on the current objectives of the project such that roller probe withstands most preheat/post-heat conditions and operates a time period comparable to the standard HT wedge assemblies.

To this end, a time-transient multi-physics model was created to simulate conductive, convective and radiative heat propagation. The tire thickness was parameterized to vary from $1 \mathrm{~mm}$ to $10 \mathrm{~mm}$ with unit increments. The measured thermal and mechanical properties of rubber material HTSilicone S20A were incorporated into the physics model. To make the FEM computationally efficient, a simplified 2Dsymmetric model of the roller was prepared assuming that the thermodynamics were consistent along the roller probe's axis of rotation - see Figure 8. 


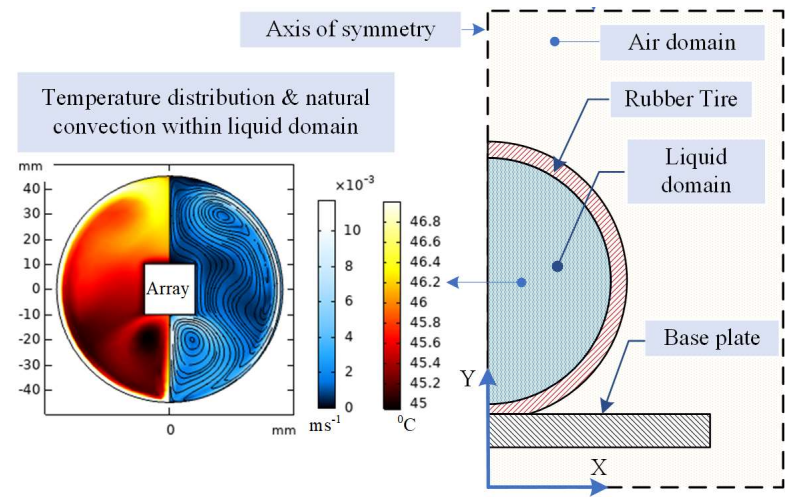

Fig. 8. The 2D illustration of time-transient model and its graphica results indicating temperature $\left({ }^{\circ} \mathrm{C}\right)$ distribution, and fluid flow velocity contours $\left(\mathrm{ms}^{-1}\right)$ within the roller probe when tire thickness is $6 \mathrm{~mm}$.

The boundary conditions, initial values and materials stated in Table 2 were considered in this simulation. It was assumed that the roller travels at a speed of $\sim 1.6 \mathrm{~mm} / \mathrm{s}$ following the weld torch. As a result, the effect of mechanical mixing within the liquid domain was neglected. Further, natural convection in stagnant air was assumed for the roller probe's external domain. Above assumptions were made to simulate the critical heat dissipation scenario. Based on these criterions, a nonisothermal laminar fluid flow was approximated for gas/liquid domains. The contact width of the tire-metal surface was considered to be $10 \mathrm{~mm}$ such that it was equal to the width of PAUT transducer's active area. The ratio between the maximum size of a given mesh element and tire thickness is maintained constant at 0.03 throughout simulations.

TABLE 2

MATERIALS, INITIAL AND BOUNDARY CONDITIONS OF THERMAL MODEL

\begin{tabular}{llll}
\hline \hline Domain & Material & Boundary conditions & Initial values \\
\hline $\begin{array}{l}\text { Liquid } \\
\text { Tire }\end{array}$ & $\begin{array}{l}\text { Water } \\
\text { Rubber }\end{array}$ & $\begin{array}{l}\text { Closed domain } \\
\text { Natural convection in } \\
\text { stagnant air } \\
\text { Constant temperature } \\
\text { with natural convection } \\
\text { is stagnant air }\end{array}$ & $25^{\circ} \mathrm{C} \mathrm{\&} \mathrm{1.2} \mathrm{atm}$ \\
& Steel & $\begin{array}{l}{ }^{\circ} \mathrm{C} \\
\text { Open boundary at room } \\
\text { conditions }\end{array}$ & $25^{\circ} \mathrm{C} \mathrm{\&} \mathrm{1} \mathrm{atm}$ \\
\hline \hline
\end{tabular}

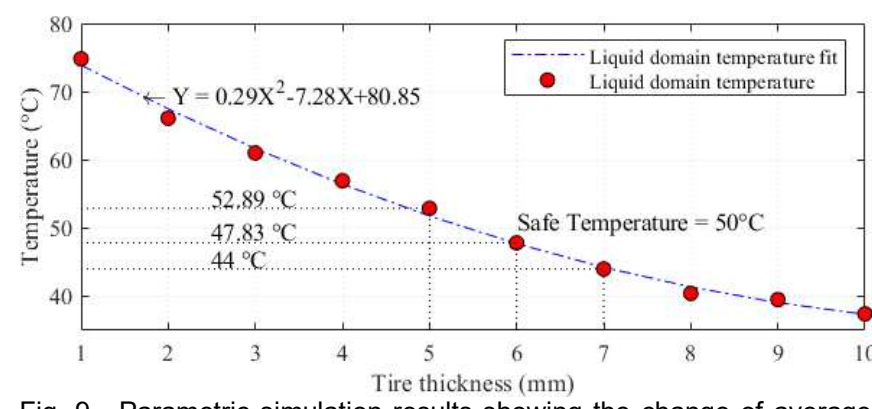

Fig. 9. Parametric simulation results showing the change of average temperature of the liquid domain as the tire thickness varies. The duration of the time-transient model was 10 mins.

The results of the parametric study are given in Figure 9 as the variations of liquid domain's temperature versus the tire thickness. Here, it can be observed that the average temperature within the liquid domain exceeds $50{ }^{\circ} \mathrm{C}$ for any tire thicknesses smaller than $5 \mathrm{~mm}$. The graph implies that a tire thickness of at least $5 \mathrm{~mm}$ is critical to keep the array safe. When the tire thickness is increased to $6 \mathrm{~mm}$ and $7 \mathrm{~mm}$, the average temperature of the liquid domain reaches $47.83{ }^{\circ} \mathrm{C}$ and $44{ }^{\circ} \mathrm{C}$, respectively. Therefore, it was decided to proceed with a $6 \mathrm{~mm}$ thick tire for which a total of $10.4 \mathrm{~dB}$ attenuation at frequency of $5 \mathrm{MHz}$ was measured using the setup explained in II.B.

\section{E. Ultrasound modelling and simulation}

\section{1) Inspection position relative to the weld}

It is important to determine the roller probe's position relative to the weld to generate a sector scan such that the nearest weld groove surface to the roller probe is fully covered. As recommended by ISO13588:2019, the direction of the incident beam to the bevelled surface normal should remain $\pm 6^{\circ}$ to provide the best inspection performance [1]. For this purpose, an industrially relevant inspection of a 15 $\mathrm{mm}$ thick steel substrate with $90^{\circ} \mathrm{V}$-groove was assumed to allow determination of the roller probe's position from the weld centre. Given the roller probe's physical dimension, fullskip wave propagation to the weld was considered. As shown in Figure 2, the upper extremity (UE) and lower extremity (LE) beams of the sectorial scan are considered in the calculations.

The stand-off of the first array element from the inner tire surface was determined by the mechanical assembly constraints described in II.A and fixed at $40 \mathrm{~mm}$. By assuming an $84^{\circ}$ incident angle between the bevelled surface and the beam reaching the top of the bevelled surface according to [1] and using the material properties listed in Table 3 , a $39^{\circ}$ refraction angle was determined. Subsequently, the angle of incidence of the highest beam in the range that is refracted by $\theta$ was calculated and the derived value was examined to ensure the beam direction did not violate recommended limits.

TABLE 3

MATERIAL PROPERTIES USED IN THE ANALYTICAL MODEL

\begin{tabular}{cccc}
\hline \hline Material & $\begin{array}{c}\text { L wave Velocity } \\
\left(\mathrm{ms}^{-1}\right)\end{array}$ & $\begin{array}{c}\text { T wave Velocity } \\
\left(\mathrm{ms}^{-1}\right)\end{array}$ & $\begin{array}{c}\text { Density } \\
\left(\mathrm{kgm}^{-3}\right)\end{array}$ \\
\hline Water & 1480 & - & 1000 \\
Rubber & 1001 & - & 1050 \\
Steel & - & 3240 & 7800 \\
\hline \hline
\end{tabular}

The non-linear relationship given in (1) was derived considering the geometry of Figure 2 where $x=12.14 \mathrm{~mm}$, $y=15 \tan \theta, \quad z=1.5 \tan \theta, \quad \alpha=\frac{\sin \theta \times 1480}{3240}, \quad \beta=\frac{\sin \theta \times 1001}{3240}$ and $\mathrm{d}$ is given by (2). The refraction angle of upper sectorial beam is estimated to be $50.8^{\circ}$ by solving (1) numerically. This resulted in an $84.2^{\circ}$ incident angle to the weld groove, which is within the recommended tolerances. Therefore, a $35^{\circ}-75^{\circ}$ sectorial scan with a single roller probe position of $62 \mathrm{~mm}$ away from the weld centre was determined to be possible.

$$
4 x+13.5=3 y+z+d
$$

$$
d=\left\{49 \tan ^{-1}\left[\sin ^{-1}(\alpha)\right]+6 \tan ^{-1}\left[\sin ^{-1}(\beta)\right]\right\}-15
$$

\section{2) Array pose estimation}

As sectorial scan beams exit the tire from different axial locations depending on the beam angle, the array needs to be positioned within the roller probe such that it allows all sectorial beams to propagate into the material. The array's orientation was set in a manner to generate a $55^{\circ} \mathrm{T}$ beam 
within a steel test component when the beam is unsteered (i.e. when no focal law is applied). To determine the array orientation inside the roller, a semi-analytical ray tracing model was prepared to replicate the roller probe weld inspection as illustrated in Figure 2. The model consists of three simplified domains, a water domain representing roller probe's filler material, an intermediate rubber layer corresponds to the tire, and a steel test component - see Figure 10 (a). According to the Snell's law, a $22^{\circ}$ tilt angle is required for the array to generate $55^{\circ} \mathrm{T}$ wave inside the steel test component.

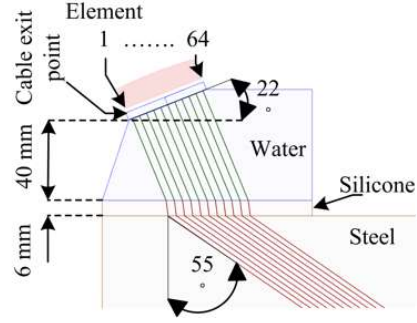

(a)

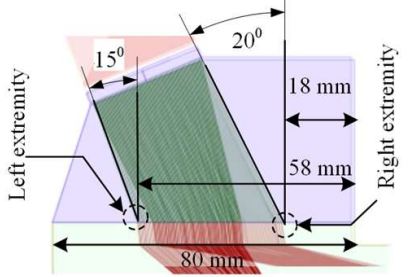

(b)
Fig. 10. A semi-analytical model prepared to (a) investigate the optimized height and orientation of the array inside the wheel for generating $55^{\circ}$ shear wave when there is no delay laws applied, and (b) indicate the extent of the acoustic window at the rubber/sample interface when a sectorial sweep of $35^{\circ}$ and $75^{\circ}$ is desired.

Therefore, it was only required to determine its axial position within the roller probe. For this purpose, a sectorial scan of $35^{\circ}$ to $75^{\circ}$ with increments of $1^{\circ}$ was simulated. The ultrasound beams were focused at a distance of $90 \mathrm{~mm}$ in the steel sample, measured from the wedge middle point. In Figure 10 (b), the transverse beams of rays of $35^{\circ}$ and $75^{\circ}$ are represented by 64 individual rays that are connected to each array element. Every ray is directed at a different orientation depending on the time delays applied to the corresponding element. The innermost ray of the $35^{\circ}$ beam starts, and the outermost ray of the $75^{\circ}$ beam ends the acoustic window. The measurements on the model suggest that the window is about $40 \mathrm{~mm}$ long when the array standoff is $40 \mathrm{~mm}$.

\section{EXPERIMENTAL SETUPS}

\section{A. High temperature experimental setup}

The internal temperature distribution of the roller probe was experimentally examined to validate the thermal model and to determine the initial time limit for a continuous inspection of a weld plate with a given temperature. The maximum allowable temperature within probe's liquid domain was imposed by the continuous operational temperature of the existing ultrasound transducer, which is limited to $50{ }^{\circ} \mathrm{C}$. A carefully planned test bed, which comprised a roller probe with a thermistor carriage, a base plate placed over two heating blankets, a sixaxis KUKA KR6 articulated robot and a closed loop temperature controller for the heaters was developed for this purpose - see Figure 11 (a) and (b). The thermistor carriage which is shown in Figure 11 (c) consists of five immersion thermistors, which were calibrated to have an error less than $1.05^{\circ} \mathrm{C}$. This carriage was positioned such that the thermistors were aligned to the vertical central plane of the roller probe.
Here, a LabVIEW program was used to control the robot through an external PC using ITRA toolbox [21]: (i) to contact the heated base plate using the roller probe, (ii) to manipulate the roller probe back and forth over $400 \mathrm{~mm}$ travel along Xaxis at a velocity of $1.6 \mathrm{mms}^{-1}$, (iii) to $\log$ temperatures at a 2 $\mathrm{Hz}$ frequency using a NI USB-6008 device, and (iv) to retract the robot to a safe position when the mean temperature within the liquid domain exceeds a threshold $55^{\circ} \mathrm{C}$.

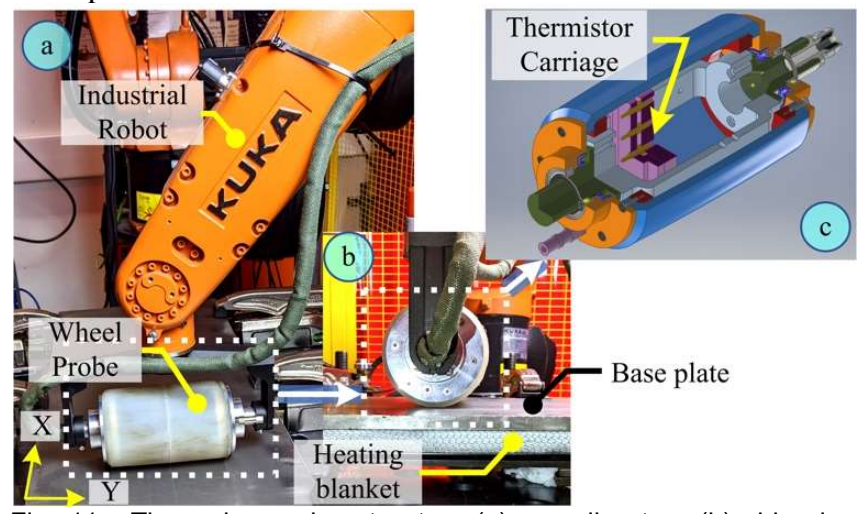

Fig. 11. Thermal experiment setup: (a) overall setup; (b) side view illustrating physical configuration of heating blankets and base plate; (c) internal view of the roller probe that encompasses thermistor carriage.

\section{B. In-process inspection setup for multi-pass welds}

In-process weld inspection capability of the PAUT roller probe was assessed using the setup shown in Figure 12 (a). The multirobot testbed developed comprised a KUKA KR5 arc HW robot for welding and a KUKA KR6 robot for NDT delivery using the roller probe. A Tungsten Inert Gas (TIG) welder was used to perform a $400 \mathrm{~mm}$ long butt-weld on 15 $\mathrm{mm}$ thick structural steel (S275) plates with $90^{\circ} \mathrm{V}$-groove geometry. The roller probe orientation around the $\mathrm{Y}$ axis was calibrated at room temperature using a B-type phased array calibration block made of steel [22]. The roller probe's offset along $\mathrm{Y}$ axis from the centre of the weld geometry was estimated in II.E.1 and validated using an in-house weld calibration block with $2 \mathrm{~mm}$ diameter SDH - see Figure 12 (b). The same calibration block was used to estimate the inprocess PAUT controller gain which was $55 \mathrm{~dB}$. A LTPA array controller by PEAK NDT [23] with 64Tx/64Rx channels was used with drive voltage of $150 \mathrm{~V}$ and $2 \mathrm{kHz}$ pulse repetition frequency (PRF).

Artificial weld defects using tungsten tubes and rods were introduced into the weld to evaluate the performance of the PAUT roller probe - see Figure 12 (c). Here, $T_{1}$ represents a tungsten tube with $2 \mathrm{~mm}$ internal diameter (ID) and $3 \mathrm{~mm}$ outer diameter (OD), $\mathrm{T}_{2}$ represents a tungsten rod with $1.6 \mathrm{~mm}$ $\mathrm{OD}$ and $\mathrm{T}_{3}$ is a tungsten rod with $2.4 \mathrm{~mm}$ OD. These defects were embedded to the weld in layer 4 , after pass 5 , and in layer 5 , after pass 11 . The $T_{1}$ tungsten pipe was placed off towards the bevelled surface while $T_{2}$ and $T_{3}$ tungsten rods were placed at the centre of the weld by retaining them inside approximately $4 \mathrm{~mm}$ deep circular notches with widths of 1.8 $\mathrm{mm}$ and $2.4 \mathrm{~mm}$ respectively. A schematic of the weld layout is present in Figure 12 (c). As shown in the same figure, four thermocouples $\left(\mathrm{TC}_{\mathrm{n}}, \mathrm{n}=1, \ldots, 4\right)$ were attached to the weld plate to monitor the weld plate temperature during the 
deposition. As the two weld plates are identical in geometry and material, it was assumed that both plates have similar temperature distributions.

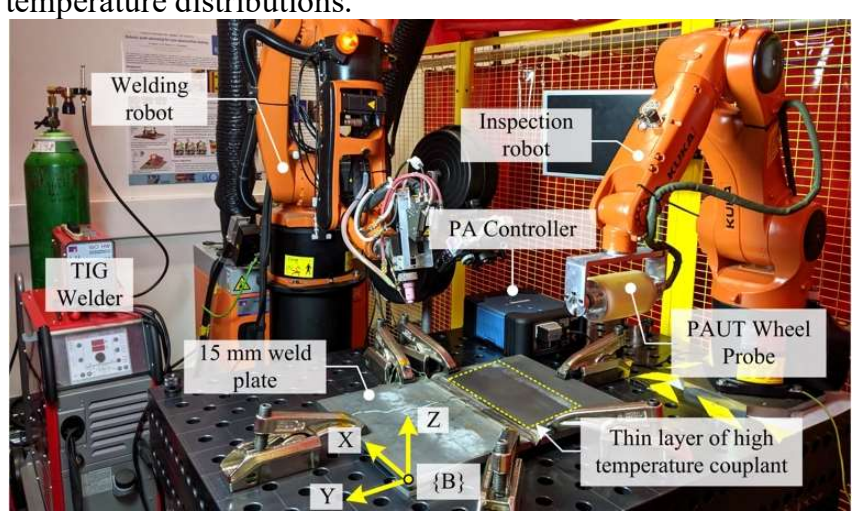

(a)

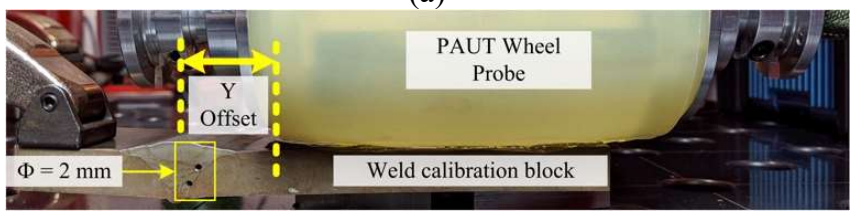

(b)

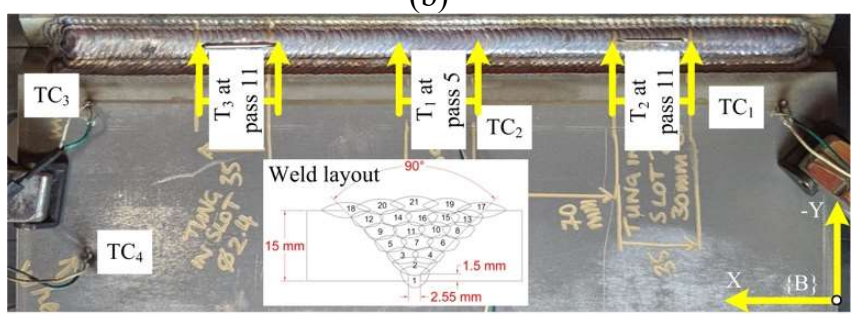

(c)

Fig. 12. (a) In-process weld inspection setup which comprises a TIG welder, a welding robot, the PAUT roller probe mounted to an inspection robot, $15 \mathrm{~mm}$ thick weld plates and a phased array controller, (b) central plane offset estimation using weld calibration block and (c) Artificial defect and thermocouple map. Here four thermocouples $\left(\mathrm{TC}_{n}, \mathrm{n}=1, \ldots, 4\right)$ were mounted on the weld plate.

The welder, two robots, PAUT controller and ultrasound data acquisition were controlled using a LabVIEW program executed on a local computer and a field-programmable gate array. Here, a $35^{\circ}-75^{\circ}$ sectorial scan delay law was created using $55^{\circ} \mathrm{T}$ wave into the weld geometry with $0.5^{\circ}$ pitch. A very thin layer of Olympus H-2 high temperature gel was used to acoustically couple the PAUT roller probe to the weld plate [24]. The control program allowed the inspection robot to start inspection after finishing each pass only if the temperatures measured by all thermocouples were less than $350{ }^{\circ} \mathrm{C}$ and the weld robot was retracted to a safe position. A $230 \mathrm{~mm}$ long continuous scan was performed. The inspection data were acquired based on a pre-defined sampling distance along the $\mathrm{X}$ axis.

\section{RESULtS AND DisCUSSION}

\section{A. High temperature experiment results}

The mean internal temperature of the roller probe against continuous scan time for individual base plate temperatures is shown Figure 13. It was observed that the roller probe could perform continuous travel for almost 40 mins when the base plate was at $150{ }^{\circ} \mathrm{C}$. The inspection time window decreased according to the second order decay function given in (3) where $t$ is the continuous inspection time in minutes and $T$ is the base plate temperature in ${ }^{\circ} \mathrm{C}$. The manufacturer recommended maximum long exposure temperature of tire material is $350{ }^{\circ} \mathrm{C}$ where the roller probe performed a continuous travel for 11.17 mins. This result closely agrees with the output of the finite element model described in Section II.D.

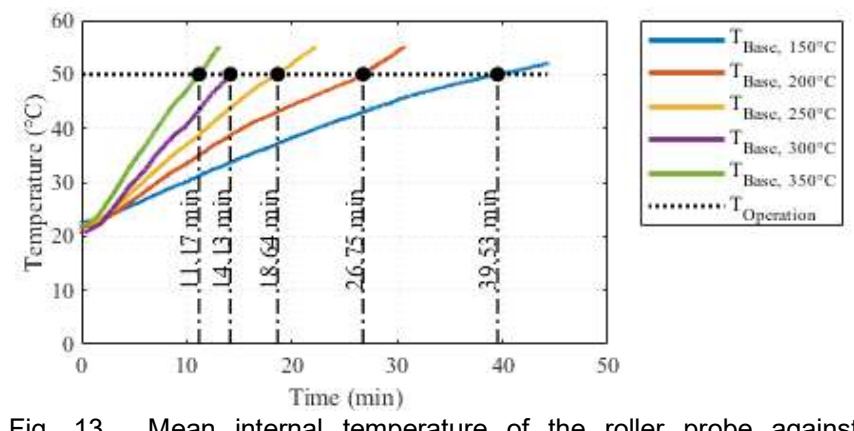

Fig. 13. Mean internal temperature of the roller probe against continuous scan time at different base plate temperatures.

$$
T=144.6 \times e^{-0.0094 T}+3.705 \times e^{0.0013 T}
$$

\section{B. Comparison of roller probe performance with commercial hardware.}

Performance of the PAUT roller probe in terms of signal amplitude, signal to noise ratio (SNR) and spatial resolution was compared with Olympus SA32C-ULT-N55S-IHC wedge and a $5 \mathrm{MHz}-5 \mathrm{~L} 64-\mathrm{A} 32$ array referred to as commercial PAUT hardware hereon. Both assemblies were configured to generate $35^{\circ}-75^{\circ} \mathrm{T}$ wave sectorial scans with $0.5^{\circ}$ pitch into the test material using the same LTPA array controller with $150 \mathrm{~V}$ excitation voltage and $2 \mathrm{kHz}$ PRF.

\section{1) Signal Amplitude}

The weld calibration block illustrated in Figure 12 (b) is used to compare the signal amplitudes. Here, the hardware gain of each assembly was set to have the maximum AScan amplitude of the top $2 \mathrm{~mm} \mathrm{SDH}$ at $80 \%$ of the screen height. The roller probe demonstrated a $-4.5 \mathrm{~dB}$ signal amplitude as compared to the commercial PAUT hardware. It is proposed, as expected, that the reduction in signal amplitude is predominantly attributed to the rubber tire of the roller probe.

2) Signal to noise ratio (SNR)

The SNR of the roller probe is compared against the SNR of commercial PAUT hardware by analysing $\triangle S N R$ according to (4) where $S_{R P}, N_{R P}, S_{C H}$ and $N_{C H}$ are the maximum amplitude of signal and maximum amplitude of noise measured for the roller probe and the commercial PAUT hardware, respectively. The signal was recorded using the weld calibration block. The roller probe demonstrated an $18.06 \mathrm{~dB}$ SNR with $\triangle S N R=-6.02 \mathrm{~dB}$.

\section{3) Spatial resolution}

$$
\Delta S N R=20\left[\log \left(\frac{S_{R P}}{N_{R P}}\right)-\log \left(\frac{S_{C H}}{N_{C H}}\right)\right]
$$

The spatial resolution of the roller probe is compared to the commercial hardware using a B-type carbon steel phased array calibration block [22]. Shown in Figure 14 (a) and (b) are the experimental arrangement using roller probe and commercial hardware respectively. An array of $18 \mathrm{SDHs}$ on $25 \mathrm{~mm}$ radius 
at $1.0 \mathrm{~mm}$ diameter with $5^{\circ}$ angular separation was used. The beam exit point was aligned with the centre of array of SDHs. Shown in Figure 14 (c) and (d) are the sector scan images of SDHs captured using roller probe and commercial PAUT hardware respectively.

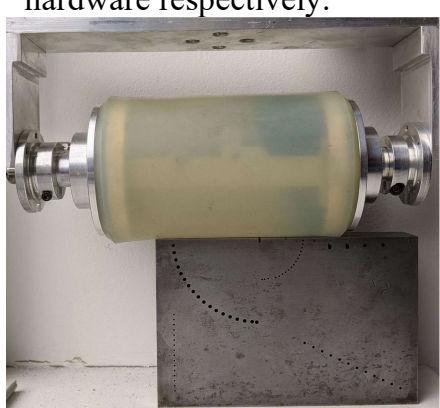

(a)

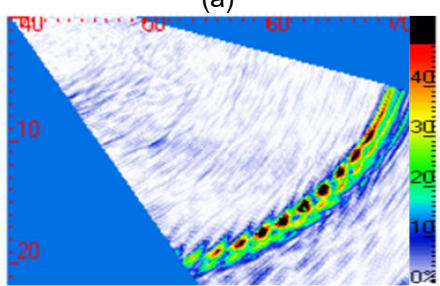

(c)

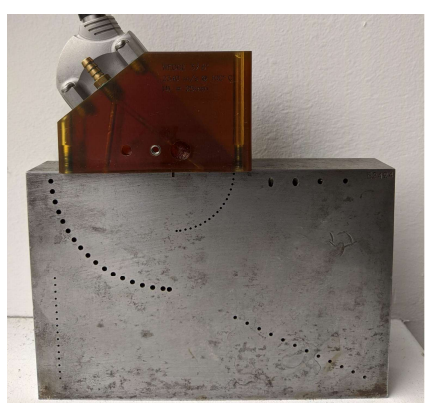

(b)

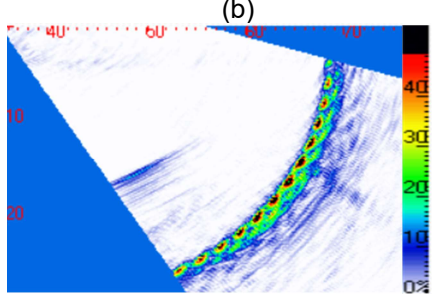

(d)
Fig. 14. Spatial resolution comparison using B-type carbon steel phased array calibration block (a) physical arrangement roller probe, (b) physical arrangement of commercial hardware, (c) sector scan image using roller probe and (d) sector scan image using commercial hardware.

The hardware gain in both experiments were adjusted such that maximum signal amplitude is $80 \%$ of the screen height and a standard $6 \mathrm{~dB}$ amplitude measurement was considered. Both the roller probe and the commercial PAUT hardware detected $12 / 18$ holes with a $35^{\circ}-75^{\circ}$ sectorial scan. As can be seen, the SDHs detected by the higher beam angles in the roller probe's sectorial scan were less resolved as compared to the scan from the commercial PAUT hardware and it is concluded that this is due to the presence of the tire intermediate rubber layer.

\section{Effect of elevated temperature}

Based on the authors' prior work [14], it was observed that the received signal amplitude from an artificially embedded $2.6 \mathrm{~mm}$ OD tungsten rod defect, of length $38 \mathrm{~mm}$ in a weld increased by $4.08 \mathrm{~dB}$ when the sample cooled down from 164 ${ }^{\circ} \mathrm{C}$ to $28{ }^{\circ} \mathrm{C}$. Also, for the same reference temperature boundaries, the defect position on a sector scan image moved by approximately $3 \mathrm{~mm}$. This phenomenon can be explained by the variation of acoustic wave velocity in solid media, such as steel, with temperature [25]. It was shown in [6,26], that the temperature gradient present after weld deposition caused the ultrasound beams to deviate from their expected path due to the velocity variation and subsequent beam refraction, affecting defect sizing, amplitude and localisation. Calibration trials of the roller-probe at elevated temperature showed a $6.34 \mathrm{~dB}$ amplitude drop of the received signal amplitude from a $2 \mathrm{~mm}$ diameter $\mathrm{SDH}$ in a representative weld, at $240{ }^{\circ} \mathrm{C}$ compared to room temperature of $22{ }^{\circ} \mathrm{C}$. It is therefore proposed that the elevated temperatures and thermal gradients expected and encountered during in-process inspection will produce a similar reduction in received signal amplitude when compared to nominal room temperature calibration data.

\section{In-process inspection results using PAUT roller probe assembly}

All artificial defects $T_{1}$ to $T_{3}$ embedded in the weld were successfully detected using sectorial scanning method where the ultrasound signal took two full skips to reach the weld. Due to the partially filled welds observed during the inprocess inspection, a stronger signal from the bevelled edge (indicated as $\mathrm{BE}$ in Figure 15) relative to the defect was visible. Therefore, it is important to distinguish this false positive artefact from a true indication of a defect. To overcome this challenge, a weld geometry overlay was created and mapped on to the sector scan images [13]. Other sources of potential errors include effect of temperature variations and gradients, the presence of air bubbles within roller probe's liquid domain and poor coupling between the roller probe's tire and the substrate plate.

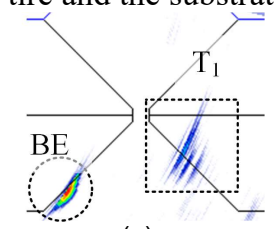

(a)

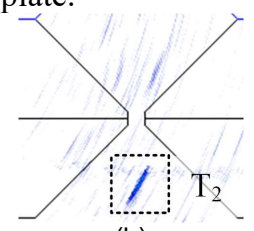

(b)

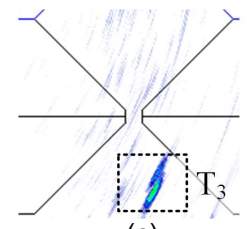

(c)
Fig. 15. Sectorial scan images of the artificial defects buried in the weld: (a) defect $T_{1}$, (b) defect $T_{2}$ and (c) defect $T_{3}$.

The maximum weld plate temperature observed during all depositions was $\sim 240{ }^{\circ} \mathrm{C}$ and this allowed the inspection robot to start immediately after the weld robot retracted to a safe position. All sector scan image amplitudes reported below are relative to the peak amplitudes observed in the calibration. The UT scan image indicating artificial defect $T_{1}$ is shown in Figure 15 (a). The base temperature measured by the central thermocouple $\mathrm{TC}_{2}$ was approximately $140{ }^{\circ} \mathrm{C}$ when the roller probe reaches $\mathrm{T}_{1}$ defect. The scan amplitude of $\mathrm{T}_{1}$ defect was measured as $37.5 \%$ compared to the calibration reference amplitude. Shown in Figure 15 (b) and (c) are the UT scan images indicating defects $T_{2}$ and $T_{3}$ respectively. Ultrasound data for defect $T_{2}$ was recorded when the base plate temperature was approximately $185{ }^{\circ} \mathrm{C}$. In this instance, the sectorial scan amplitude was decreased to $34 \%$.

$$
\text { TABLE } 4
$$

UT SIGNAL FROM INDIVIDUAL DEFECT AND SUBSTRATES TEMPERATURE

\begin{tabular}{cccc}
\hline \hline Defect & Type and size & $\begin{array}{c}\text { Amplitude w.r.t } \\
\text { calibration }\end{array}$ & Temperature \\
\hline $\mathrm{T}_{1}$ & $\begin{array}{c}\text { Tube with ID }=2 \mathrm{~mm} \\
\text { and OD }=3 \mathrm{~mm}\end{array}$ & $-8.52 \mathrm{~dB}$ & $140{ }^{\circ} \mathrm{C}$ \\
& Rod with OD $=1.6 \mathrm{~mm}$ & $-9.37 \mathrm{~dB}$ & $185^{\circ} \mathrm{C}$ \\
$\mathrm{T}_{2}$ & Rod with OD $=2.4 \mathrm{~mm}$ & $-5.68 \mathrm{~dB}$ & $230^{\circ} \mathrm{C}$ \\
$\mathrm{T}_{3}$ & R
\end{tabular}

The ultrasound data of defect $T_{3}$ was recorded when the base plate was at $230{ }^{\circ} \mathrm{C}$. It was observed that the sectorial scan amplitude to be $52 \%$. Summarised in Table 4 are the defect, its nature, signal amplitude with respect to (w.r.t) the calibration signal and weld plate temperature when the UT data were acquired. As illustrated in the images, the PAUT roller probe provided artefact free images. This suggests that the roller probe maintained noise or geometrical reflections to 
a minimum, and that the bulk of acoustic energy emitted from array was transferred to the material.

\section{V.CONCLUSIONS AND FUTURE WORK}

This paper has presented the design, development and validation of a HT roller probe to perform robotically enabled in-process inspection of multi-pass fusion welds using PAUT. The PAUT roller probe described in this paper addresses key challenges associated with in-process inspection of multi-pass welds such as: (i) high temperature, (ii) ability to perform continuous angled weld inspection using an ultrasound phased array, (iii) automation capability using off-the-shelf robotic manipulators, and (iv) ability to conform to surface and geometric complexities.

The experimental results presented here demonstrate that this PAUT roller probe was able to inspect each weld pass immediately after the deposition and to identify artificial defects introduced into the welded joint. These defects provided indications comparable to a calibration sample. In contrast to off-the-shelf PAUT roller probes, this novel roller probe endures surface temperatures up to $350{ }^{\circ} \mathrm{C}$. The PAUT presented here only requires a very thin film of high temperature couplant. The PAUT roller probe described in this paper:

1.Demonstrates the ability to tolerate weld plate surface temperatures up to $350{ }^{\circ} \mathrm{C}$ for more than 10 minutes.

2. Performs $55^{\circ} \mathrm{T}$ wave angled weld inspection using PAUT technology.

3. Requires only a very thin layer of ultrasound couplant and provides a good SNR with minimum artefacts obstructing any indication of real defects.

4. Was employed to perform inspections immediately after deposition of each pass in a multi-pass weld for the purpose of validation. It was found that the roller probe was successful in detecting all intentionally embedded defects where the highest inspection temperature was recorded as $\sim 230^{\circ} \mathrm{C}$

As there is an emerging commercial requirement for inprocess inspection of welds, it is expected to industrialise the roller probe in the future and integrate into a fully automated inspection system. Compensation for the reduction in received signal amplitude due to the elevated temperature and thermal gradients present in in-process inspection, and its effect on wave velocity and refraction, was not considered in this body of work but future activity will seek to address these significant challenges through wave propagation understanding and compensation. The authors believe that industrial implementation of this roller probe will provide greater opportunities to reduce cycle time, down time and waste linked to current fusion welding and inspection practices.

\section{REFERENCES}

[1] ISO13588:2019, Non-destructive testing of welds - Ultrasonic testing Use of automated phased array technology, International Organization for Standardization, 2019.

[2] ISO19285:2017, Non-destructive testing of welds - Phased array ultrasonic testing (PAUT) - Acceptance levels, International Organization for Standardization, 2017
[3] ISO17640:2017, Non-destructive testing of welds - Ultrasonic testing Techniques, testing levels, and assessment, International Organization for Standardization, 2017.

[4] Z. Wang, "An imaging and measurement system for robust reconstruction of weld pool during arc welding," IEEE Transactions on industrial electronics, vol. 62, 2015, pp. 5109-5118.

[5] X. Li, X. Li, S.S. Ge, M.O. Khyam, and C. Luo, "Automatic welding seam tracking and identification," IEEE Transactions on Industrial Electronics, vol. 64, 2017, pp. 7261-7271.

[6] D.I. Lines, Y. Javadi, E. Mohseni, M. Vasilev, C.N. MacLeod, R.W. Vithanage, Z. Qiu, R. Zimermann, C. Loukas, E. Foster, and others, "Flexible robotic cell for in-process inspection of multi-pass welds," NDT2019, 2019, pp. 1-12.

[7] Y. Javadi, C. MacLeod, D. Lines, M. Vasilev, E. Mohseni, E. Foster, Z. Qiu, R. Vithanage, R. Zimermann, C. Loukas, and others, "In-process inspection of multi-pass robotic welding," 46th Review of Progress in Quantitative Nondestructive Evaluation Conference, 2019.

[8] C. Camerini, J. Rebello, L. Braga, R. Santos, T. Chady, G. Psuj, and G. Pereira, "In-Line Inspection Tool with Eddy Current Instrumentation for Fatigue Crack Detection,” Sensors, vol. 18, 2018, p. 2161.

[9] A. Bulavinov, R. Pinchuk, S. Pudovikov, and C. Boller, "Ultrasonic sampling phased array testing as a replacement for X-ray testing of weld joints in ship construction," Proceedings of the 9th International Navigational Symposium on Marine Navigation and Safety of Sea Transportation, Gdynia, Poland, 2011, pp. 91-94.

[10]M. Moles, N. Dubé, S. Labbé, and E. Ginzel, "Review of ultrasonic phased arrays for pressure vessel and pipeline weld inspections," Journal of pressure vessel technology, vol. 127, 2005, pp. 351-356.

[11]B.W. Drinkwater and P.D. Wilcox, "Ultrasonic arrays for non-destructive evaluation: A review," Ndt \& E International, vol. 39, 2006, pp. 525-541.

[12]D. Huggett, M. Dewan, M. Wahab, A. Okeil, and T. Liao, "Phased array ultrasonic testing for post-weld and online detection of friction stir welding defects," Research in Nondestructive Evaluation, vol. 28, 2017, pp. $187-210$.

[13]T. Kim, Z. Cui, W.-Y. Chang, H.-W. Kim, Y. Zhu, and X. Jiang, "Flexible 1-3 Composite Ultrasound Transducers with Silver Nanowirebased Stretchable Electrodes," IEEE Transactions on Industrial Electronics, 2019.

[14]Y. Javadi, E. Mohseni, C.N. MacLeod, D. Lines, M. Vasilev, C. Mineo, E. Foster, S.G. Pierce, and A. Gachagan, "Continuous monitoring of an intentionally-manufactured crack using an automated welding and inprocess inspection system," Materials \& Design, 2020, p. 108655.

[15]B.W. Drinkwater and C.J. Brotherhood, "Coupling element with varying wall thickness for an ultrasound probe," 2008.

[16]E. El-Banna, "Effect of preheat on welding of ductile cast iron," Materials Letters, vol. 41, 1999, pp. 20-26.

[17]O. CORPORATION, "Ultrasonic phased array wedge for inspecting high-temperature parts up to $150^{\circ} \mathrm{C}$," Mar. 2016 .

[18]T. Okabe, Y. Jin, and B. Sendhoff, "A critical survey of performance indices for multi-objective optimisation," The 2003 Congress on Evolutionary Computation, 2003. CEC'03., IEEE, 2003, pp. 878-885.

[19]E. Ginzel and B. Turnbull, "Determining approximate acoustic properties of materials," NDT. net Dec, 2016.

[20]R. Consultants, Rubber Consultants.

[21]C. Mineo, M. Vasilev, C.N. MacLeod, R. Su, and S.G. Pierce, "Enabling robotic adaptive behaviour capabilities for new industry 4.0 automated quality inspection paradigms," 57th Annual British Conference on NonDestructive Testing, 2018, pp. 1-12.

[22]I. 2400:2012, Non-destructive testing - Ultrasonic testing Specification for calibration block No. 1, International Organization for Standardization, 2012.

[23]P. NDT, PEAK LTPA.

[24] Olympus, Safety Data Sheet, Olympus Europa SE \& Co. KGWendenstraße 14-1820097 HamburgGermany: 2018.

[25]S.F. Biagiotti and others, "Effect of temperature on ultrasonic velocity in steel," Corrosion97, NACE International, 1997.

[26]Y. Javadi, N.E. Sweeney, E. Mohseni, C.N. MacLeod, D. Lines, M. Vasilev, Z. Qiu, R.K. Vithanage, C. Mineo, T. Stratoudaki, and others, "In-process calibration of a non-destructive testing system used for inprocess inspection of multi-pass welding," Materials \& Design, 2020, p. 108981 . 


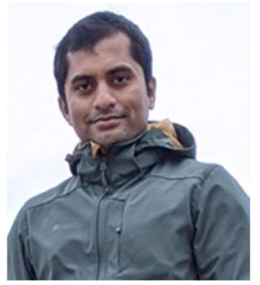

Dr Randika Vithanage is a Knowledge Exchange Fellow / Senior R\&D Engineer in Centre for Ultrasonic Engineering (CUE) at the University of Strathclyde. He is an award winning chartered engineer with over 10 years of highly successful experience working in the high-value manufacturing industry and academia. Hi primary research focus is on robotically enabled nondestructive testing in manufacturing, nuclear, energy and assets monitoring sectors. Dr. Vithanage has a strong engagement with the industry, and currently, he leads a number of fundamental and high technology readiness research funded by Innovate UK, EPSRC and BEIS.

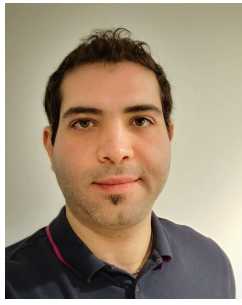

Dr. Ehsan Mohseni is a Lecturer in applied sensing and signal processing in CUE at the University of Strathclyde. He received his Ph.D. degree in Non-Destructive Evaluation (NDT\&E) from the École de Technologies Supérieure, Montreal, Canada in 2018. His research interest has been predominantly focused on automated NDT\&E of metallic and composite components using acoustic and electromagnetic testing methods. Currently, he supports Royal Academy and Spirit AeroSystems Research Chair in automated NDT\&E by leading the research and developments in the automated high-temperature in-process inspection of additive manufacturing through robotically delivered eddy current testing.

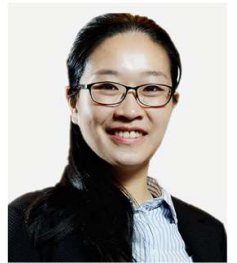

Dr Zhen Qiu is a research associate in CUE at the University of Strathclyde. Her research interests are focused on the development of ultrasonic transducers and arrays for a broad range of applications including NDT in heavy industry sectors, biomedical therapy and imaging. Her current research is to develop high-temperature ultrasonic array transducers to stand the harsh environment encountered during the deployment of in-process inspection of fusion welding

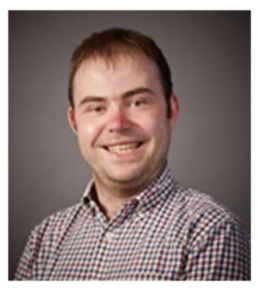

Dr Charles MacLeod is a Senior Lecturer in CUE at the University of Strathclyde. His research is primarily associated with the inspection and manufacturing enhancement of high-value assets, where he leads a number of high-profile inter-disciplinary inprocess welding and metal-additive research projects. He has driven and co-developed core robotic and ultrasonic technology from fundamental EPSRC research, which is now being deployed and licensed by leading industrial organisations and co-developed an innovative inspection robot for a critical life-extension inspection at Sellafield Reprocessing Facility.

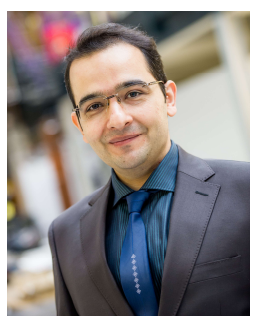

Dr Yashar Javadi is a Strathclyde Chancellor's Fellow at the University of Strathclyde. The multidisciplinary nature of his work has been reflected in the joint appointment between the Department of Electronic \& Electrical Engineering and the Department of Design, Manufacturing \& Engineering Management. In a career spanning over 15 years in the field of engineering, he has worked as a lecturer and postdoctoral research associate in the academia and also as a manager of the welding/NDT department and welding engineer in the industry. He has published 65 refereed technical articles (including 37 journal papers), with h-index of 17 and 971 citations in total as of Nov 2020. Currently, his research focus is on the inprocess inspection and residual stress measurement in the additive manufacturing.

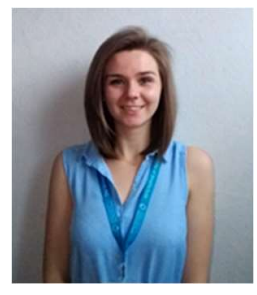

Nina Sweeney is an Engineering Doctorate (EngD) student in the Centre for Ultrasonic Engineering (CUE) at the University of Strathclyde.

Her research concentrates on enhancing the use of ultrasonic inspection equipment to facilitate real-time inspection and control of fusion welding processes, with a specific focus on Tungsten Inert Gas (TIG) welding.

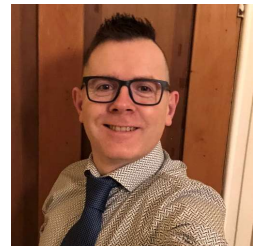

Professor Gareth Pierce is the Spirit AeroSystems/Royal Academy of Engineering Research Chair for "In-process Non-destructive Testing for Composites". Currently, he leads a multidisciplinary team at University of Strathclyde comprising Electrical and Mechanical Engineers, Mathematicians, Physicists and Bioengineers. He promotes collaborative research through an international network of academic partners and promotes impact though relationships with multi sector industry partners and the High Value Manufacturing Catapult Centres in the UK. Based in the CUE, the focus of his work is robotics and autonomous systems for inspection, including non-destructive testing and evaluation for manufacture, and structural health monitoring for asset inspection. The multidisciplinary nature of his work brings together robotics, instrumentation and interfacing, applied optics, ultrasonics, 3D metrology and machine learning based data management.

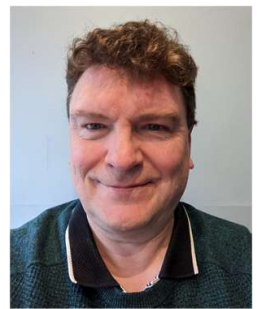

Professor Anthony Gachagan is the Director of the CUE \& Associate Dean Postgraduate Research, at the University of Strathclyde, and Co-Director of the EPSRC CDT in FUSE, jointly held with University of Glasgow. He has worked in the field of ultrasonic engineering for $\sim 30$ years across a broad application range including NDE, sonar, bioacoustics, health, manufacturing and industrial process control. He has published $>140$ papers, with his primary research interests centred on transduction: ultrasonic transducers and arrays, non-contact ultrasonic sensors, array imaging processing, high power ultrasound systems, and acoustic emission. 